\title{
Nutrition risk in the child and adolescent population of the Basque country: the enKid Study
}

\author{
Javier Aranceta Bartrina ${ }^{1} *$, Lluis Serra-Majem ${ }^{2}$, Carmen Pérez-Rodrigo ${ }^{1}$, Lourdes Ribas-Barba ${ }^{3}$ and \\ Alfonso Delgado-Rubio 4 \\ ${ }^{1}$ Community Nutrition Unit, Bilbao Department of Public Health, Luis Briñas 18, 4th floor, E-48013 Bilbao, Spain \\ ${ }^{2}$ Department of Preventive Medicine and Public Health, University of Las Palmas, Las Palmas, Spain \\ ${ }^{3}$ Unit of Research on Community Nutrition, Scientific Park University of Barcelona, Barcelona, Spain \\ ${ }^{4}$ Department of Pediatrics, University of the Basque Country, Bilbao, Spain
}

\begin{abstract}
Cross-sectional population studies provide valuable information for nutrition surveillance and planning intervention strategies. The enKid Study is the largest nutrition survey on the child and adolescent Spanish population to date. In the present paper, nutrition risks in children and young people of the Basque country based on the enKid Study subsample for the Basque region are presented. Dietary assessment was completed by means of a $24 \mathrm{~h}$ recall and a food frequency questionnaire completed in an interview with the mother or caregiver for children under 13 years. A second $24 \mathrm{~h}$ recall was completed on $25 \%$ of the sample. Body weight, height and circumference were measured on each individual. Overweight and obesity were defined using Cole et al. cut-offs. Fat intake supplied $40 \%$ of energy intake and saturated fats $13 \cdot 8 \%$. Overall, $80 \%$ of the sample had intakes of fat above $35 \%$. Main food sources of fats were added fats (32\%), meat (20\%) and milk products (20\%). Buns, cakes and pastry supplied $11 \%$ of total fat intake. The nutrients showing the highest proportion of people who did not reach one third (33\%) of the Spanish dietary reference intake levels were vitamin D, vitamin E, vitamin A and folate. Prevailing food pattern showed a high consumption of meat and meat products, milk, dairy products and cereals. Conversely, consumption of fruit, vegetables and fish was low; in fact, $89 \%$ of the sample had a normal consumption of fruit and vegetables below five portions a day. Prevalence of obesity was estimated at $3.94 \%$, and $17.85 \%$ of the sample was classified as overweight.
\end{abstract}

Dietary survey: Child nutrition: Nutrition risk: Obesity: Population studies

Nutrition during childhood is essential for appropriate growth and development. An increasing body of evidence suggests that diet and life-style factors in this stage of life have a potential lifelong effect on risk factors for many chronic diseases such as obesity, CHD, hypertension, diabetes and some types of cancer (Kemm, 1987; Nicklas et al. 1988). Furthermore, some cohort studies among children and young people show tracking of dietary patterns in this period and their influence on those prevailing in later life (Wang et al. 2002).

In recent years, obesity has become a major public health problem in most developed countries (World Health Organization, 2000). Of major concern is its spread among the youngest population groups (Lobstein et al. 2004). Information from cross-sectional population studies is of great value for the identification and prioritization of problems in a public health context. Such studies provide valuable information on dietary patterns, nutritional intake, proportion of the population meeting nutrition recommendations, the prevalence of overweight and obesity, inactivity and additional relevant information. Understanding determinants and other behavioural facts is relevant for the design and implementation of preventive action plans.
Dietary assessment in cross-sectional population studies needs a compromise between adequate precision of the estimate and what is feasible within given time and resource constraints. The most commonly used dietary data collection methods are interviewer-administered $24 \mathrm{~h}$ recalls, self-administered food records and food frequency questionnaires. Variation within each individual in dietary intake is one of the most important estimation issues, as has long been recognized (Beaton et al. 1979; Sempos et al. 1985). Mean $1 \mathrm{~d}$ intakes by individuals in a group can be an unbiased estimate of the group's usual mean intake, but only if the single days are a good representation of all days (Guenther et al. 1997).

In the last decade, an intense debate has arisen regarding nutrient intake recommendations and a major conceptual shift has occurred, from a nutrient deficit prevention approach to the health-enhancing potential of a nutrient adequacy approach.

The enKid Study is the largest nutrition study carried out on a representative random sample of the Spanish child and adolescent population (2-24 years), covering all geographical regions in the country (Serra Majem \& Aranceta Bartrina, 2000). Information from this study has been an important tool for community nutrition action in Spain over recent years.

Abbreviations: BMR, basal metabolic rate; CHO, carbohydrate; DRI, dietary reference intake; EAR, estimated average requirements; EI, energy intake; SFA, saturated fatty acids.

*Corresponding author: Dr J. Aranceta, fax +34 94 4204466, email jaranceta@unav.es 
The present paper focuses on nutrition risks in children and young people of the Basque country based on the enKid Study subsample for the Basque region. The purpose of this study is to assess inadequate nutrient intake, to identify major food intake patterns and to determine the prevalence of obesity and overweight in this population.

\section{Methods}

\section{Study sample}

The enKid Study is a population-based, observational cross-sectional study carried out on a random sample of the Spanish population aged 2-24 years. The sample was drafted by a multiple step sampling procedure based on the population census of residents aged 2-24 years. The theoretical sample size for the whole study was set at 5500 individuals, considering an anticipated participation rate of $70 \%$. The sampling technique included stratification by geographical area and size of municipality of residence, further randomized into subgroups. Municipalities were the primary sampling unit and individuals within the municipality the final units in the sample.

The sample of the Basque country was oversized in order to get an adequate sample size representative for the region. The theoretical sample size for the Basque country was set at 1100 individuals to get estimates with a sampling error lower than $3 \%$. Analysis of results in this subsample is the basis for this study.

\section{Dietary assessment}

Dietary intake was assessed by means of a $24 \mathrm{~h}$ recall. Information was collected at the home of the participant, using household measures to estimate portion sizes. Additional information on food descriptions and portion sizes was gathered as required on site. A second $24 \mathrm{~h}$ recall in an independent non-consecutive day was completed in a random $25 \%$ of the sample in order to assess day-to-day intra-individual variation in dietary intake.

Day-of-collection data were randomly assigned throughout weekdays, including weekends and non-school days. Data collection was completed covering all seasons of the year (May 1998-April 2000). Data were collected by trained dietitians during a personal interview with each participant and their mother or caregiver responsible for feeding the child for those under 13 years.

Additionally, a 164-item food frequency questionnaire was completed for each participant. The study questionnaire included questions on dietary habits, consumption of supplements, physical activity on weekdays as well as leisure time, tobacco and alcohol use, food preferences and a questionnaire on beliefs and information regarding food- and nutritionrelated issues (Aranceta et al. 2002; Pérez-Rodrigo et al. 2002).

\section{Anthropometrical measurements}

Anthropometrical measurements were assessed on each individual following standard protocols (Serra-Majem et al. $2001 a, b$ ). Body weight, height and circumferences were measured on the day of the interview, with the subject in underwear without shoes, using an electronic scale (to the nearest $100 \mathrm{~g}$ ), a portable Kawe stadiometer (to the nearest $1 \mathrm{~mm}$ ) and an inextensible Hoescht metric tape (to the nearest $1 \mathrm{~mm}$ ). Measuring devices were systematically calibrated.

Observers followed an intensive training period to familiarize themselves with the protocol, procedures to follow and standardization of criteria before beginning the fieldwork. In this study, overweight and obesity have been defined based on BMI, computed as body weight $(\mathrm{kg})$ divided by the squared height (m), using Cole et al. (2000) cut-offs according to a reference population percentile distribution of BMI specific for age and sex.

\section{Additional variables}

The study protocol included socioeconomic family background considering the level of education and occupation of the mother and father. The educational level was later classified as low (less than 8 years of education completed), medium (between 8 and 12 years of education completed) or high (more than 12 years of education completed). The professional occupation of the parents was considered under a common hierarchial structure. This information was used to define three levels (lowmedium-high) of family socioeconomic status, according to the methodology described by the Spanish Society of Epidemiology (Álvarez Dardet et al. 1995).

All questionnaires were specially designed for the study and were previously pretested and validated (Serra Majem \& Aranceta Bartrina, 2000). All field workers followed a training period prior to data collection. Fieldwork was completed between May 1998 and April 2000. The study protocol was approved by the ethical committee of the Spanish Society of Community Nutrition. Parental consent was requested for each participant.

\section{Statistical analysis}

Nutrient intakes in this study were estimated based on the $24 \mathrm{~h}$ recall data. The specific nutrient database software used consisted of the Spanish food composition database by Mataix et al. (1998) completed with information from the McCance \& Widdowson food composition tables (Holland et al. 1991).

Data from the $24 \mathrm{~h}$ recall were adjusted for intra-individual variability using the method described by Liu et al. (1978) in order to estimate usual nutrient intakes, after cubed root transformation in order to achieve normality of the distributions. The data were back-transformed after adjustment. Basal energy expenditure was calculated using gender-ageweight-specific equations computed by Schofield (1985). Dietary reporting status was assessed by computing a ratio of reported energy intake (EI) to calculated basal metabolic rate (BMR; Goldberg et al. 1991). Low reporters were defined in this study as those with EI:BMR below 1.14.

Prevalence of inadequate nutrient intake was estimated as the proportion of population groups below a cut-off level of recommended intakes, considering the dietary reference intake (DRI) values for the Spanish population (Consejo Superior de Investigaciones Científicas, 1994). For comparison purposes, the estimated average requirements (EAR) cut-off method approach using EAR nutrient reference values from the Institute of Medicine $(2000 a, b)$ have also been used (Barr et al. 2002). 
The usual consumers of specific foods were estimated from the food frequency questionnaire, while food consumption estimates from commonly eaten foods and food groups were derived from the $24 \mathrm{~h}$ recalls. Inadequate consumption by food group was calculated by comparison with Spanish food-based dietary guidelines.

Data were analysed using the statistical package SPSS for Windows (version 12.0; SPSS Inc., Chicago, IL, USA). Descriptive statistics such as mean, standard error estimates and quartile distribution are presented for the variables considered, as well as prevalence estimates. Prevalence of inadequate consumption across groups was compared by the $\chi^{2}$ statistic for rates and proportions.

\section{Results}

\section{Participation rate}

In the Basque country, the sample was formed by 847 individuals aged $2-24$ years, 399 boys (mean age 15.3 (SE 6.4) years) and 448 girls (15.2 (SE 6.3) years), resulting in a $77 \%$ participation rate. Response rate within the region varied from $70.3 \%$ in Araba to $80.7 \%$ in Bizkaia. Participation was lower among boys $(70.8 \%)$ than girls $(83.4 \%)$. Table 1 shows the characteristics of respondents in the sample according to subgroups used in this analysis (age, sex, family socioeconomic status, region).

\section{Energy and nutrient intake}

After adjustment for intra-individual variability, EI:BMR was computed and individuals with a ratio $<1 \cdot 14$ were excluded from this analysis. Such low ratios are considered very unlikely as the usual energy intakes do not satisfy energy requirements, and rather they are considered to be underreporters according to the $24 \mathrm{~h}$ recall. Valid records from 718 individuals were included in this analysis, 350 boys and 368 girls.

Distribution of energy and macronutrient intake by age and sex group is presented in Table 2. Mean energy intake shows a profile harmonically growing with age to reach a peak at $10-$ 13 years in girls and at $14-17$ years in boys. Cereals $(31 \%)$ and milk products $(20 \%)$ were the main sources of energy in the diet, followed by meat and meat products (15\%), sweets $(14 \%)$ and added fats $(14 \%)$.

Fat intake on average supplied $40 \%$ of energy intake; saturated fatty acids (SFA) $13.8 \%$, MUFA $16.6 \%$ and PUFA $6.1 \%$. Overall, $29 \%$ of the sample had intakes of fat that contributed between 35 and $39 \%$ of energy and in $51.7 \%$ of the sample fat intake supplied $40 \%$ of energy in the diet or more. This proportion was significantly higher in girls and children aged 2-5 years $(58 \%)$. In the youngest age group, $48 \%$ of the sample had fat intakes above $40 \%$ of energy intake. Main sources of fats in the diet were added fats which contributed to $32 \%$ fat intake, meat $(20 \%)$ and milk products (20\%). Buns, cakes and pastry supplied $11 \%$ of total fat intake.

Regarding SFA, $55 \%$ of the sample had intakes in the range which supplied 10-14\% energy from SFA, and overall less than $12 \%$ of the sample had SFA intakes contributing less than $10 \%$ energy to the diet. The pattern was similar in boys and girls. Main sources of SFA in the diet were dairy products $(34.6 \%)$, meat and meat products $(22 \%)$ and buns, cakes and pastry $(14 \%)$.

Table 1. Characteristics of participants; enKid Study - Basque country

\begin{tabular}{|c|c|c|c|c|c|c|}
\hline & \multicolumn{6}{|c|}{ enKid Study - Basque country sample } \\
\hline & \multicolumn{2}{|c|}{ Total } & \multicolumn{2}{|c|}{ Boys } & \multicolumn{2}{|c|}{ Girls } \\
\hline & $n$ & $\%$ & $n$ & $\%$ & $n$ & $\%$ \\
\hline \multicolumn{7}{|l|}{ Age group } \\
\hline $2-5$ years & 82 & 9.68 & 44 & 11.03 & 38 & 8.48 \\
\hline $6-9$ years & 104 & $12 \cdot 28$ & 54 & 13.53 & 50 & $11 \cdot 16$ \\
\hline $10-13$ years & 142 & $16 \cdot 77$ & 73 & $18 \cdot 30$ & 69 & $15 \cdot 40$ \\
\hline $14-17$ years & 160 & $18 \cdot 89$ & 80 & 20.05 & 80 & $17 \cdot 86$ \\
\hline $18-24$ years & 359 & $42 \cdot 38$ & 148 & 37.09 & 211 & $47 \cdot 10$ \\
\hline Total & 847 & $100 \cdot 00$ & 399 & $100 \cdot 00$ & 448 & $100 \cdot 00$ \\
\hline \multicolumn{7}{|l|}{ Region } \\
\hline Bizkaia & 477 & $56 \cdot 32$ & 247 & 61.90 & 230 & $51 \cdot 34$ \\
\hline Araba & 109 & $12 \cdot 87$ & 42 & 10.53 & 67 & 14.96 \\
\hline Gipuzkoa & 261 & $30 \cdot 81$ & 110 & 27.57 & 151 & 33.71 \\
\hline Total & 847 & $100 \cdot 00$ & 399 & $100 \cdot 00$ & 448 & $100 \cdot 00$ \\
\hline \multicolumn{7}{|l|}{ Size of municipality } \\
\hline$<10000$ inhabitants & 64 & 7.56 & 33 & 8.19 & 31 & 6.94 \\
\hline $10000-50000$ inhabitants & 62 & $7 \cdot 27$ & 34 & 8.19 & 28 & $6 \cdot 36$ \\
\hline $50000-350000$ inhabitants & 428 & $50 \cdot 58$ & 205 & 51.46 & 223 & 49.71 \\
\hline$>350000$ inhabitants & 293 & 34.59 & 127 & $32 \cdot 16$ & 166 & 36.99 \\
\hline Total & 847 & $100 \cdot 00$ & 399 & $100 \cdot 00$ & 448 & $100 \cdot 00$ \\
\hline \multicolumn{7}{|l|}{ Family SES level } \\
\hline Low & 124 & 14.66 & 58 & 14.50 & 67 & 14.84 \\
\hline Medium & 503 & $59 \cdot 38$ & 234 & 58.75 & 269 & 60.05 \\
\hline High & 220 & $25 \cdot 96$ & 107 & $26 \cdot 75$ & 112 & $25 \cdot 11$ \\
\hline Total & 847 & $100 \cdot 00$ & 399 & $100 \cdot 00$ & 448 & $100 \cdot 00$ \\
\hline
\end{tabular}

SES, socioeconomic status. 


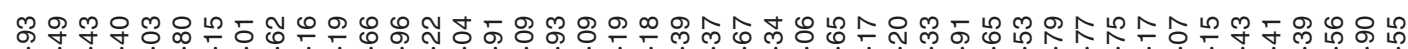

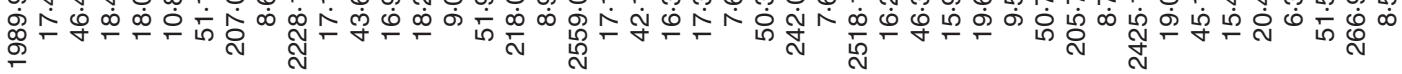
$\stackrel{0}{\circ}$

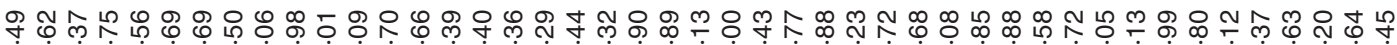

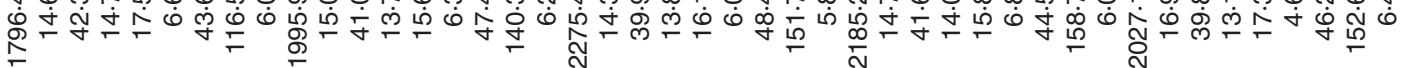

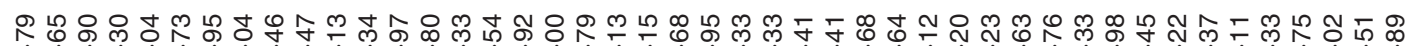

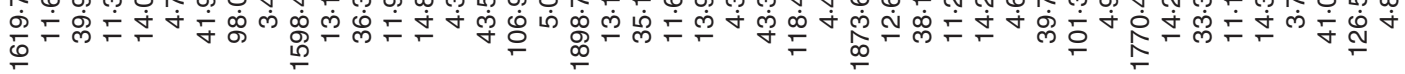

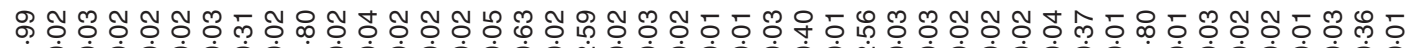
두 भ -

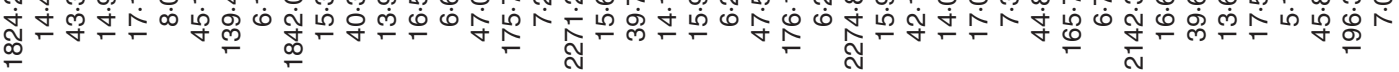

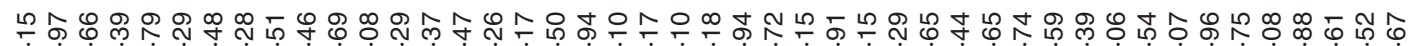

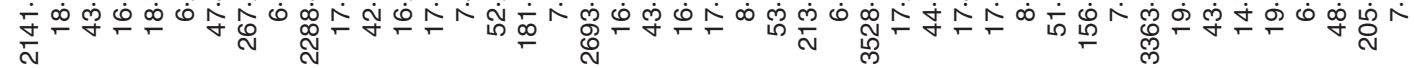

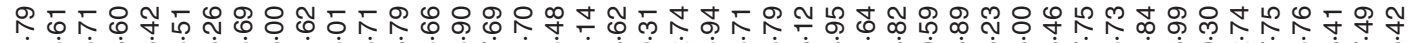

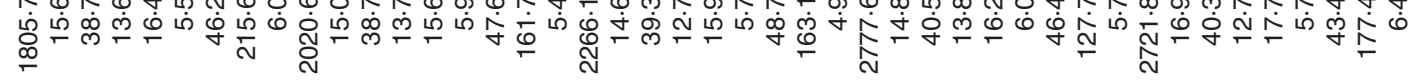

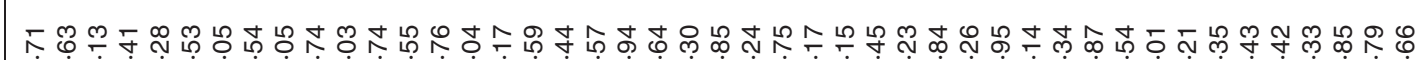

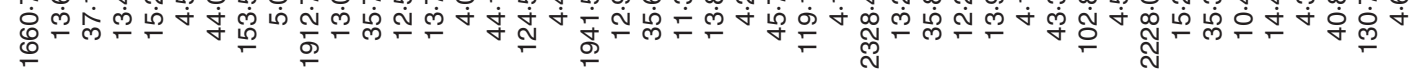

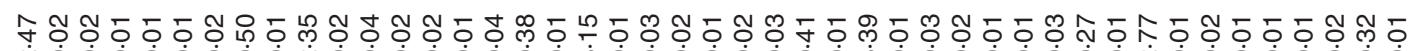

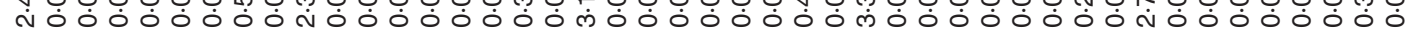

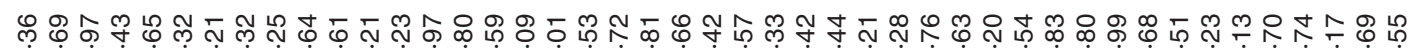

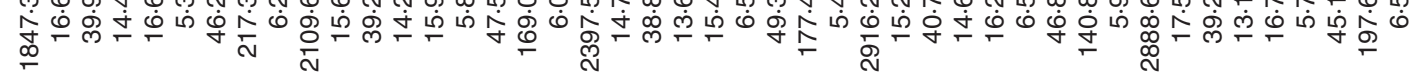

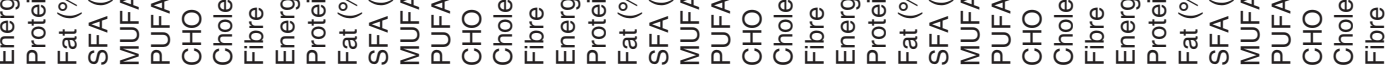


Total carbohydrates (CHO) supplied $46 \%$ of the total energy intake and $43.7 \%$ of the sample had $\mathrm{CHO}$ intakes that supplied less than $45 \%$ of energy intake. Less than $1 \%$ of girls in the age group 18-24 years had CHO intakes below the estimated requirements according to the Institute of Medicine, set at $100 \mathrm{~g}$.

On average, protein intake supplied $16 \%$ of energy intake, $16.3 \%$ in boys and $15.8 \%$ in girls. In $2 \%$ of the sample, protein intake supplied less than $10 \%$ energy of the diet; for $14.2 \%$ protein intake supplied more than $20 \%$ of energy intake, but intake levels above $30 \%$ energy from protein were limited to $0 \cdot 1 \%$.

In the male group, mean fibre intake ranged from $11.5 \mathrm{~g}$ in boys aged $2-5$ years up to $18.5 \mathrm{~g}$ in the oldest age group. In the female group, fibre intake was lowest in girls 2-5 years $(12.7 \mathrm{~g})$ and increased with age up to a mean value of $15.3 \mathrm{~g}$ in the age group 14-17 years. As nutrient density, this intake level varied between $5.4 \mathrm{~g} / 1000 \mathrm{kcal}$ and $6.5 \mathrm{~g} / 1000 \mathrm{kcal}$ among boys across age groups and between $6.1 \mathrm{~g} / 1000 \mathrm{kcal}$ and $7.3 \mathrm{~g} / 1000 \mathrm{kcal}$ in girls. Overall, $59.3 \%$ of the sample had fibre intakes under $15 \mathrm{~g} / \mathrm{d}$. In the female subgroup, $7.4 \%$ had fibre intakes above $25 \mathrm{~g} / \mathrm{d}$. In the male subgroup, $7 \cdot 1 \%$ had fibre intakes above $30 \mathrm{~g} / \mathrm{d}$.

Food consumption with breakfast supplied $17.5 \%$ of daily energy intake. Lunch, i.e. the early afternoon meal, was the main meal of the day. Food consumption at this time of the day contributed $33.5 \%$ of total energy intake; the afternoon snack supplied $14.9 \%$ and dinner was $25.9 \%$ of energy intake. However, $4.5 \%$ of the sample did not have any breakfast on the day reported. Furthermore, $4.4 \%$ reported usually they did not have any breakfast. This rate was higher in boys $(7.3 \%)$ than girls $(3.2 \%)$. A high proportion of those having breakfast, $70 \%$, usually had incomplete breakfasts where fruits were missing.

\section{Risk of inadequate micronutrient intake}

For the present analysis, only dietary intake has been considered, but not supplements. From the general questionnaire, $21.8 \%$ of the sample reported consumption of some supplement in the past 12 months, $27.9 \%$ in girls and $15.7 \%$ boys. The use of supplements was more common in the older age group, $18-24$ years $(28.9 \%)$.

The estimates were performed on intake levels adjusted for intra-individual variability, thus on estimated usual intake. Mean intake of $\mathrm{Fe}, \mathrm{Zn}$, vitamin $\mathrm{A}$, vitamin $\mathrm{E}$ and vitamin $\mathrm{D}$ were lower than Spanish recommended dietary intakes. The nutrients showing the highest proportion of people who did not reach one-third of the Spanish DRI levels were vitamin $\mathrm{D}$, vitamin $\mathrm{E}$, vitamin $\mathrm{A}$ and folate. The highest rates of people who did not reach two-thirds of Spanish DRI levels were observed for the same nutrients, as well as for vitamin $\mathrm{C}$, vitamin $\mathrm{B}_{6}, \mathrm{Fe}, \mathrm{Ca}, \mathrm{Mg}$ and $\mathrm{Zn}$. The risk for inadequate intakes was higher in the female subgroup for $\mathrm{Fe}, \mathrm{Ca}, \mathrm{Zn}$, folate and vitamin E (Table 3).

Considering the EAR cut-off approach, the estimated prevalence of inadequate intake was higher for $\mathrm{Mg}$, folate, vitamin $\mathrm{C}$, vitamin $\mathrm{E}$ and vitamin $\mathrm{D}$. Prevalence of inadequate intake of folate was significantly higher among girls.
Table 3. Percentage of children and young people in the Basque country whose daily nutrient intake was below cut-off levels (less than two-thirds of the Spanish dietary reference intake) by sex (enKid Study - Basque country)

\begin{tabular}{lcccc}
\hline Dietary component & All & Boys & Girls & Significance level* $^{*}$ \\
\hline Vitamin A & 43.1 & 45.6 & 40.3 & $\mathrm{NS}$ \\
Vitamin C & 16.4 & 15.3 & 17.2 & $\mathrm{NS}$ \\
Vitamin E & 57.7 & 55.8 & 60.1 & 0.000 \\
Thiamin & 0.9 & 0.6 & 1.3 & 0.01 \\
Riboflavin & 1.2 & 1.03 & 1.5 & $\mathrm{NS}$ \\
Niacin & 1.2 & 1.3 & 1.0 & 0.01 \\
Vitamin $\mathrm{B}_{6}$ & 8.6 & 5.7 & 12.5 & 0.01 \\
Folate & 28.7 & 4.5 & 57.5 & 0.000 \\
Vitamin $\mathrm{B}_{12}$ & 0.12 & 0.2 & 0 & $\mathrm{NS}$ \\
Ca & 4.3 & 2.6 & 6.4 & 0.05 \\
Mg & 14.3 & 14.4 & 14.2 & $\mathrm{NS}$ \\
Fe & 15.1 & 2.6 & 30 & 0.000 \\
Sample size & 847 & 399 & 448 & \\
\end{tabular}

NS, not statistically significant.

* Difference among age/gender groups, determined by two-tailed test.

\section{Food consumption pattern}

The prevailing food consumption pattern shows a high consumption of meat and meat products, milk, dairy products and cereals. Conversely, consumption of fruit, vegetables and fish was low in this population group. The risk of inadequate consumption of vegetables was higher in the younger age subgroups, particularly among boys, in which more than $90 \%$ reported their usual consumption to be below recommended levels, i.e. two portions of vegetables a day. Inadequate consumption of fruit was also more frequent in boys. More than $60 \%$ of the sample reported usual consumption of fruit below two portions per day and $25.9 \%$ reported usual intakes between two and three portions per day. Overall, $89 \%$ of the sample had usual consumption of fruit and vegetables below five portions a day. Regarding dairy products, $36 \%$ of boys and girls of the study group showed inadequate consumption of milk and dairy products (fewer than four portions per day). Likewise, consumption of buns, sweets and pastry was above desirable for $47 \%$ of the sample. Table 4 shows the percentage of usual consumers by food group, mean frequency of consumption and proportion of the sample with inadequate intake according to Spanish food-based recommendations.

\section{Overweight and obesity}

Considering Cole et al. criteria to define overweight and obesity, as adopted by the International Obesity Task Force, prevalence of obesity among children and young people in the Basque country is estimated at $3.9 \%$. A total of $17.8 \%$ of the sample was classified as overweight, higher in the male subgroup (22\%). Prevalence of overweight and obesity was higher in children younger than 14 years, both in boys and girls (Table 5).

\section{Discussion}

The enKid Study is to our knowledge the first study to provide data on individually assessed anthropometrical measurements, dietary intake and life-styles in a national random population 
sample of Spanish children and young people. Furthermore, it is the first such nutrition survey carried out in this population group in the Basque country region.

The usefulness of performing such population studies is widely acknowledged to provide valuable input for monitoring and planning public health strategies. In this case, the high participation rate achieved, the careful design of the protocol and the procedures followed ensured good quality useful data.

Most recent nutrition surveys in children and adolescents in developed countries report intakes below recommendations in significant proportions of the population (Hercberg et al. 1991; Gregory \& Lowe, 2000; Tomkins, 2001; Suitor \& Gleason, 2002). This is also the case for the enKid Study, both for the whole of the country and for the Basque country region. Particularly high prevalences of inadequacy were estimated for nutrients such as folate, vitamins C, A, E and D. Certainly, the methodologic issue of under-reporting that is believed to occur in dietary studies using $24 \mathrm{~h}$ recalls or food records must be addressed when interpreting the findings of this study (Livingstone \& Black, 2003). To evaluate the potential for under-reporting, we used a common method to identify under-reporters that is based on the Schofield (1985) formula for basal energy expenditure and using a cut-off for the ratio EI:BMR as developed by Goldberg et al. (1991). Their equation calculates the lower $95 \%$ confidence limit of EI:BMR assuming a given requirement for physical activity level, below which it is unlikely that the mean intake represents either habitual intake for weight maintenance or a random low intake (the Goldberg cut-off). Using this method, we found that $17 \%$ of children could be classified as under-reporters. Another methodologic issue for children is accurate reporting of dietary intake.

One study documents overestimates of energy in young males, whereas other studies indicate that $24 \mathrm{~h}$ recalls approximate energy intakes of children (Livingstone \& Black, 2003). In this case, in order to improve the accuracy of the reports, the mother or caregiver responsible for feeding the child was present during the interview with the child for those under 13 years. Furthermore, since the interviews took place at the home of the participants, it was possible to complete data on food descriptions and portion sizes according to household measures in most cases for the benefit of the information collected.

Fat intake was high in the Basque country enKid Study. This finding is consistent with the general results of the enKid Study in Spain (Serra-Majem et al. 2001a,b, 2002). It is interesting to note that the main sources of fat in the diet of Basque children were added fats, meat, milk products and buns, cakes and pastry. Similarly, the Four Provinces study conducted in a sample of 6-7-year-old children in four Spanish provinces identified olive oil and sunflower oil, French fries, whole milk, meat products and biscuits as the main sources of fat in this population group (Royo-Bordonada et al. 2003).

Among American children and young people, 34.6\% had fat intakes below $30 \%$ of energy and only $15 \%$ had sugar intakes below $10 \%$ of energy (Munoz et al. 1998). In the Basque country, fat intake is high. In fact, only $20 \%$ of the sample had fat intakes below $35 \%$. It is noteworthy, however, that added fat, particularly olive oil, is one the main sources of fat in the diet that supplied $32 \%$ of fat intake, while MUFA was $17 \%$ of total energy. 
Table 5. Prevalence of overweight and obesity in children and young people of the Basque country by age and sex according to Cole et al. cut-off criteria (2-24 years)

\begin{tabular}{|c|c|c|c|c|c|c|}
\hline & $2-5$ years $(\%)$ & $6-9$ years $(\%)$ & $10-13$ years $(\%)$ & $14-17$ years $(\%)$ & $18-24$ years $(\%)$ & Total (\%) \\
\hline \multicolumn{7}{|l|}{ Total } \\
\hline Overweight & $19 \cdot 52$ & $13 \cdot 80$ & $17 \cdot 75$ & $10 \cdot 80$ & $12 \cdot 45$ & 13.91 \\
\hline \multirow[t]{2}{*}{ Overweight + obesity } & $29 \cdot 94$ & $22 \cdot 89$ & $20 \cdot 28$ & $14 \cdot 88$ & 13.49 & $17 \cdot 85$ \\
\hline & $100 \cdot 00$ & $100 \cdot 00$ & $100 \cdot 00$ & $100 \cdot 00$ & $100 \cdot 00$ & $100 \cdot 00$ \\
\hline \multicolumn{7}{|l|}{ Boys } \\
\hline Overweight & $26 \cdot 32$ & $16 \cdot 00$ & 21.99 & $11 \cdot 62$ & 18.99 & $18 \cdot 49$ \\
\hline Obesity & $8 \cdot 07$ & $8 \cdot 13$ & 1.57 & $7 \cdot 01$ & 0.69 & 3.73 \\
\hline \multirow[t]{2}{*}{ Overweight + obesity } & 34.39 & $24 \cdot 13$ & 23.55 & $18 \cdot 63$ & $19 \cdot 68$ & $22 \cdot 22$ \\
\hline & $100 \cdot 00$ & $100 \cdot 00$ & $100 \cdot 00$ & $100 \cdot 00$ & $100 \cdot 00$ & $100 \cdot 00$ \\
\hline \multicolumn{7}{|l|}{ Girls } \\
\hline Overweight & $12 \cdot 35$ & 11.54 & $13 \cdot 14$ & 9.92 & $4 \cdot 35$ & $8 \cdot 73$ \\
\hline Obesity & $12 \cdot 89$ & $10 \cdot 07$ & 3.57 & 0.97 & 1.47 & $4 \cdot 18$ \\
\hline \multirow[t]{2}{*}{ Overweight + obesity } & $25 \cdot 24$ & $21 \cdot 60$ & $16 \cdot 71$ & $10 \cdot 89$ & $5 \cdot 82$ & $12 \cdot 91$ \\
\hline & $100 \cdot 00$ & $100 \cdot 00$ & $100 \cdot 00$ & $100 \cdot 00$ & $100 \cdot 00$ & $100 \cdot 00$ \\
\hline
\end{tabular}

George et al. (1993) found that in New Zealand, 10-11year-old boys received $36 \%$ and 10-11-year-old girls received $35 \%$ of their total daily energy from fat, with SFA providing $16 \%$ and PUFA $4 \%$ of energy. The evening meal provided the greatest proportion of fat for both girls and boys in this survey (George et al. 1993). The same study found milk and milk products contributed $18 \%$ of total fat intake. In a study on preschool children, $27 \%$ of total fat intake came from milk and milk products (McMahon, 1990). Data from the Australian National Nutrition Survey (Australian Bureau of Statistics, 1995) showed intakes comparable to those of New Zealand, i.e., energy intake from fat was $34 \%$ for 12-15-year-olds and $32 \%$ for 16-18-year-olds. Snacks, including some fast foods, can also be major contributors of daily fat intake. Data from the UK show that fried potatoes (crisps and chips) contribute $13 \%$ of the total fat intake of teenagers aged 16-17 years (Crawley, 1993).

The findings on nutrient inadequacy are consistent with the overall food consumption pattern estimated. A high proportion of children and adolescents reported inadequate consumption of fruit and vegetables. Five per cent of the sample reported that they never consumed any vegetables at all and in more than $9 \%$ this was the case for vegetable salads. Eighty-nine per cent of the sample did not meet the recommendation of five portions of fruit and vegetables. Other studies, such as the Pro Children Study, which assessed fruit and vegetable consumption in 11-13-year-olds in nine European countries including Spain, showed similar results (Yngve et al. 2005). In the Pro Children Study, Spain and Iceland reported the poorest consumption of fruit and vegetables.

A study among American children and young people found mean food group intakes for the youth population as a whole below even minimum recommendations for all food groups, except for the dairy group (Munoz et al. 1998). In this study the percentage of children meeting the recommendations for each food group ranged from $30 \%$ for fruit, grain, dairy and meat, to $36 \%$ for vegetables. In the enKid Study, both at national level and in the Basque country, consumption of milk and dairy products is adequate in a high proprotion of the population. In the Basque country, $13 \%$ of the sample had less than two portions of the dairy group every day.
Most surveys show that fruit juices, citrus fruit, other kinds of fruit and vegetables are the main sources of vitamin $\mathrm{C}$ in children's diets. This is the case in the enKid Study in the Basque country. Nevertheless, in significant proportions of the population, estimated intake levels were below twothirds of Spanish DRI or were even below EAR cut-offs. In fact, it is worth noting that fruit and vegetable consumption was inadequate in a high proportion of the sample. Conversely, consumption of sweet and salted snacks, buns, cakes and pastry was above desirable. These foodstuffs were reported mainly as part of the mid-morning or afternoon snacks, but also supplied $25 \%$ of energy with breakfast, $31 \%$ for the afternoon snack and $18 \%$ as part of other snacks during the day.

Suitor and Gleason (2002) estimated $78.9 \%$ of American children had vitamin E intakes below EAR levels. Prevalence of inadequate intakes in this survey was high for folates (50.6\%) and also $\mathrm{Mg}(36.5 \%)$. Females aged 14-18 years were the subgroup showing the highest rates of inadequate intakes. Overall, inadequate intakes of vitamin $\mathrm{C}$ in the American study were identified in $10.2 \%$ of the sample, $22 \%$ in girls aged 14-18 years. Low intakes of vitamins A, C and $\mathrm{Mg}$ tend to reflect low intakes of fruits and vegetables. Vitamin $\mathrm{E}$ is a shortfall nutrient for a high proportion of children and young people in the enKid Study in the Basque country. Current intake levels are likely underestimated because of the under-reporting of food intake on dietary surveys, especially related to the intake of fats and oils, and the limitations of nutrient databases with regard to the vitamin E content of foods as has been reported (Institute of Medicine, 2000a; Maras et al. 2004).

A number of epidemiological studies using data obtained from national surveys suggest that energy-dense, nutrientpoor foods may displace nutrient-dense foods, potentially reducing the consumption of foods from other foods groups to lower levels than recommended and limiting the ability to achieve recommended nutrient intakes (Kant and Schatzkin, 1994; Kant, 2000, 2003).

Estimated prevalence of obesity in Basque children and youth population was high. Furthermore, compared with previous estimates in studies carried out in children in Bilbao 
in 1988,95 th percentile for BMI has increased from 19.1 to $21.1 \mathrm{~kg} / \mathrm{m}^{2}$ at the age of 6 years in boys and from 18.5 to $20.4 \mathrm{~kg} / \mathrm{m}^{2}$ in girls. The shift at the age of 13 years was from 24.9 to $26 \cdot 8 \mathrm{~kg} / \mathrm{m}^{2}$ for boys and from 25.9 to 27.5 $\mathrm{kg} / \mathrm{m}^{2}$ for girls over the past 15 years, a trend similar to that seen for the whole of the country, comparing data from the PAIDOs study performed in 1985 . The estimated prevalence of obesity in Spanish children aged 6-13 years in the mid1980 s was $6.4 \%$. In the year 2000 , compared with the same reference standards, prevalence of obesity in this age group has doubled to $13.9 \%$.

\section{Conclusions}

Fat intake is high in the Basque country population aged 2-24 years and $80 \%$ of the sample showed fat intakes above $35 \%$ of energy intake. More than $87 \%$ of the study group had SFA intakes $>10 \%$ of energy. Nutrient density in the average diet of this group could improve. Risk for inadequate intake was detected for $\mathrm{Ca}, \mathrm{Fe}$, vitamin $\mathrm{C}$, folate, vitamins $\mathrm{B}_{6}, \mathrm{~A}, \mathrm{E}$ and D. Food consumption pattern is characterized by a high consumption of meats and dairy products and an inadequate consumption of fruit and vegetables.

\section{References}

Álvarez Dardet C, Alonso J, Domingo A \& Regidor E (1995) La Medición de la Clase Social en Ciencias de la Salud. Barcelona: SG-Sociedad Española de Epidemiología.

Aranceta J, Pérez Rodrigo C, Ribas L \& Serra-Majem Ll (2003) Sociodemographic and lifestyle determinants of food patterns in Spanish children and adolescents: the enKid Study. Eur J Clin Nutr 57, Suppl. 1, S40-S44.

Australian Bureau of Statistics (1995) National Nutrition Survey: Selected Highlights Australia. Canberra: Commonwealth Department of Health and Family Services.

Barr SI, Murphy SP \& Poos MI (2002) Interpreting and using the dietary references intakes in dietary assessment of individuals and groups. J Am Diet Assoc 102, 780-788.

Beaton GH, Milner J, Corey P, et al. (1979) Sources of variance in 24-hour recall data: implications for nutrition study design and interpretations. Am J Clin Nutr 32, 2546-2559.

Cole TJ, Bellizzi MC, Flegal KM \& Dietz WH (2000) Establishing a standard definition for child overweight and obesity worldwide: international survey. BMJ 320, 1240-1243.

Consejo Superior de Investigaciones Científicas (1994) Tabla de Ingestas Recomendadas en Energía y Nutrientes para la Población Española. Madrid: Departamento de Nutrición, Universidad Complutense de Madrid.

Crawley HF (1993) The energy, nutrient and food intake of teenagers aged 16-17 years in Britain. 1. The energy, macronutrients and non-starch polysaccharides. Br J Nutr 70, 15-26.

George J, Brinsdon S, Paulin J \& Aitken EF (1993) What do young adolescent New Zealanders eat? Nutrient intakes of a nationwide sample of Form 1 children. NZ Med J 106, 47-51.

Goldberg GR, Black AE, Jebb SA, Cole TJ, Murgatroyd PR, Coward WA \& Prentice AM (1991) Critical evaluation of energy intake data using fundamental principles of energy physiology. 1. Derivation of cut-off limits to identify under-recording. Eur $J$ Clin Nutr 45, 569-581.

Gregory J \& Lowe S (2000) National Diet and Nutrition Survey: Young people aged 4-18 years. London: HMSO.
Guenther PM, Kott PS \& Carriquiry AL (1997) Development of an approach for estimating usual nutrient intake distributions at the population level. J Nutr 127, 1106-1112.

Hercberg S, Preziosi P, Galan P, Deheeger M, Papoz L \& Dupin H (1991) Dietary intake of a representative sample of the population of Val-de-Marne. Rev Epidemiol Sante Publ 39, 245-261.

Holland B, Welch AA, Unwin ID, Buss DH, Paul AA \& Southgate DAT (1991) McCance \& Widdowson's The Composition of Foods, 5th ed. Cambridge: Royal Society of Chemistry.

Institute of Medicine (2000a) Dietary Reference Intakes: Applications in Dietary Assessment. Washington, DC: National Academy Press.

Institute of Medicine (2000b) Dietary Reference Intakes for Vitamin C, Vitamin E, Selenium, and Carotenoids. Washington, DC: National Academies Press.

Kant AK (2000) Consumption of energy-dense, nutrient-poor foods by adult Americans: nutritional and health implications. NHANES III 1988-1994. Am J Clin Nutr 72, 929-936.

Kant AK (2003) Reported consumption of low-nutrient-density foods by American children and adolescents: nutritional and health correlates. The Third National Health and Nutrition Examination Survey (NHANES III) 1988-1994. Arch Pediatr Adolesc Med 8, 157, 789-796.

Kant AK \& Schatzkin A (1994) Consumption of energy-dense, nutrient-poor foods by the US population: effect on nutrient profiles. J Am Coll Nutr 13, 285-291.

Kemm JR (1987) Eating patterns in childhood and adult health. Nutr Health 4, 205-215.

Liu K, Stamler J, Dyer A, McKeever J \& McKeever P (1978) Statistical methods to assess and minimize the role of intra-individual variability in obscuring the relationship between dietary lipids and serum cholesterol. J Chronic Dis 31, 399-418.

Livingstone MBE \& Black AE (2003) Markers of the validity of reported energy intake. J Nutr 133, 895S-920S.

Lobstein T, Baur L \& Uauy R for the IASO International Obesity Task Force (2004) Obesity in children and young people: a crisis in public health. Obes Rev 5, Suppl. 1, 4-85.

McMahon J, Parnell W \& Spears G (1993) Diet and dental caries in preschool children. Eur J Clin Nutr 47, 794-802.

Maras JE, Bermudez OI, Qiao M, Bakun PJ, Boody-Alter EL \& Tucker KL (2004) Intake of $\alpha$-tocopherol is limited among US adults. J Am Diet Assoc 104, 567-575.

Mataix J, Mañas M, Llopis J \& Martínez de Vitoria E (1998) Tabla de Composición de Alimentos Españoles. $3^{\mathrm{a}}$ edición. Granada: Universidad de Granada.

Munoz KA, Kreb-Smith SM, Ballard-Barbash R \& Cleveland LE (1998) Food intakes of US children and adolescents compared with recommendations. Pediatrics 100, 323-329.

Nicklas TA, Farris RP, Smoak CG, et al. (1988) Dietary factors relate to cardiovascular risk factors in early life. Bogalusa Heart Study. Arteriosclerosis 8, 193-199.

Pérez Rodrigo C, Ribas L Serra-Majem L1 \& Aranceta J (2003) Food preferences of Spanish children and young people: the enKid Study. Eur J Clin Nutr 57, Suppl. 1, S45-S48.

Royo-Bordonada MA, Gorgojo L, de Oya M, et al. (2003) Food sources of nutrients in the diet of Spanish children: the Four Provinces Study. Br J Nutr 89, 105-114.

Schofield WN (1985) Predicting basal metabolic rate, new standards and review of previous work. Hum Nutr Clin Nutr 39, Suppl. 1, $5-41$.

Sempos CT, Johnson NE, Smith EL \& Gilligan C (1985) Effects of intraindividual and interindividual variation in repeated dietary records. Am J Epidemiol 121, 120-130.

Serra Majem L \& Aranceta Bartrina J (eds) (2000) Desayuno y Equilibrio Alimentario. Estudio enKid. Barcelona: Masson SA.

Serra-Majem Ll, Garcia-Closas R, Ribas L, Pérez Rodrigo C \& Aranceta J (2001b) Food patterns of Spanish schoolchildren and adolescents: the enKid Study. Pub Health Nutr 4, 1433-1438. 
Serra-Majem L1, Ribas Barba L, Aranceta Bartrina J, Pérez Rodrigo C \& Saavedra Santana P (2001a) Epidemiología de la obesidad infantil y juvenil en España. Resultados del estudio enKid (1998-2000). In Obesidad Infantil y Juvenil: Estudio Enkid, pp. 81-108 [L Serra Majem and J Aranceta Bartrina, editors]. Barcelona: Masson.

Serra-Majem L1, Ribas-Barba L, Pérez Rodrigo C, García-Closas R, Peña-Quintana L \& Aranceta J (2002) Determinant of nutrient intake among children and adolescents: results from the enKid study. Ann Nutr Metab 46, Suppl. 1, 31-38.

Suitor CW \& Gleason PM (2002) Using dietary reference intake-based methods to estimate the prevalence of inadequate nutrient intake among school-aged children. J Am Diet Assoc 102, 530-536.
Tomkins A (2001) Vitamin and mineral nutrition for the health and development of children in Europe. Public Health Nutr 4, 91-99. Yngve A, Poortvliet E, Elmadfa I, et al. (2005) Intake of fruit and vegetables in a sample of 11-year-old children in 9 European countries: the Pro Children cross-sectional survey. Ann Nutr Metab 49, 236-245.

Wang Y, Bentley ME, Zhai F \& Popkin BM (2002) Tracking of dietary intake patterns of Chinese from childhood to adolescence over a six-year follow-up period. J Nutr 132, 430-438.

World Health Organization (2000) Obesity: Preventing and Managing the Global Epidemic. Report of a WHO Consultation. Technical Report Series no. 894. Geneva: WHO. 